\title{
Linear B: a especificidade de uma evidência e sua contribuição para os estudos micênicos
}

\author{
ANA CLAUDIA TDRRALVO \\ Doutoranda do Departamento de Antropologia \\ Faculdade de Filosofia, Letras e Ciências Humanas \\ Universidade de São Paulo
}

\begin{abstract}
RESUMO: Temos dois momentos na história da arqueologia proto-histórica grega, divididos em antes e depois da descoberta dos três tipos de escrita egeana. Com o deciframento do Linear B em 1952, por Michael Ventris, e a importantíssima constatação de que a língua grafada nessa escrita era o grego, ocorre uma verdadeira revolução no quadro histórico até então estabelecido pelos arqueólogos: Creta, onde se desenvolveu a cultura minóica e cuja língua nos é desconhecida até hoje, em um certo momento de sua história, foi dominada pelos micênicos, falantes de grego vindos do continente. A partir daí, os arqueólogos começaram a trabalhar em conjunto com os epigrafistas para rescrever a história do Egeu durante o segundo milênio a.C.. Um novo universo é revelado pelos tabletes, embora eles contenham apenas registros administrativos relativos à época da destruição dos palácios onde foram encontrados. Esses tabletes fornecem dados importantes sobre a divisão territorial dos reinos micênicos; registros de oferendas com nomes de deuses, na grande maioria os do mesmo periodo histórico; divisão de trabalho; títulos de dignatários e outras informações sociais; topônimos. A cada novo tablete encontrado e a cada nova conquista epigráfica, um pouco mais da Grécia protohistórica é-nos revelada, reconstituindo-se com mais precisão o quadro histórico real desse periodo dominado pelo universo lendário e mitológico.
\end{abstract}

PALAVRAS-CHAVE: Linear B; escrita; tabletes; micênico; minóico; administração palacial; proto-história grega.

Por volta de 1900 os primeiros tabletes contendo a escrita linear B vieram à luz pelas mãos de Sir Arthur Evans, durante as escavações do palácio de Cnossos. De forma imediata, tal descoberta levou à constatação de que nesse palácio havia um controle administrativo que remontava ao século XIII a.C. A presença desses tabletes escritos também passou a marcar a principal diferença, na época, entre Cnossos, em Creta, e os palácios continentais como Micenas e Tirinto (para um panorama geral do mundo micênico cf. Chadwick, 1976; e sobre o mundo minóico cf. Evans, 1921 [Mapa 1]). A descoberta de escrita em âmbito palacial cnossiano, juntamente com as evidências arqueológicas das cidadelas continentais onde, principalmente, os objetos retirados do Círculo Tumular A de Micenas apresentavam uma grande afinidade estilística com os objetos encontrados em 
Cnossos, levou Evans a desenvolver aquela que ficou conhecida como teoria do "cretocentrismo". Evans afirmava que Cnossos foi o principal centro egeano durante toda a Idade do Bronze, tendo dominado todo o continente grego, bem como as ilhas, estabelecendo aí sua cultura. Todas as cidadelas micênicas teriam sido assim dominadas pelo soberano de Cnossos. Embora muitos discordassem dessa teoria, o peso acadêmico de Sir Arthur Evans e a falta de elementos impediam que o debate prosseguisse. Essa situação continuou a mesma até 1936, quando C. W. Blegen revelou os primeiros tabletes de argila contendo a escrita linear B, em Pilos, na Messênia (Blegen \& Rawson, 1966). Assim, com a descoberta da sala de arquivos do dito Palácio de Nestor, abriu-se novamente o debate; afinal um palácio continental também registrava sua contabilidade e, dessa forma, começou a ruir a teoria do cretocentrismo de Evans.

Duas linhas de pesquisa abriram-se com a descoberta desse novo elemento da cultura material egeana pois são possíveis dois níveis de análise. O primeiro é determinado pela própria presença física do tablete em seu contexto de achado, situação essa na qual o que está escrito sobre ele não importa tanto quanto o fato de ter sido encontrado em determinado local. O segundo nível, bem mais complexo, envolve a informação relatada por esse tablete, aquilo que a escrita está relatando. Foram necessárias mais duas décadas até que os pesquisadores pudessem ler os textos micênicos.

A fina argila utilizada para a confecção dos tabletes era originalmente cinza clara. Originalmente, pois hoje os tabletes apresentam-se na coloração cinza escura, marrom ou vermelha. Essas mudanças são devidas à temperatura e às condições de oxigenação do incêndio que, destruindo o palácio, conservou-nos através do cozimento, os tabletes que recolhemos hoje. Após terem sido escritos, esses tabletes eram arquivados em caixas de madeira ou cestos etiquetados, os quais eram organizados em prateleiras e estantes. As caixas muitas vezes recebiam uma amarração com corda e um lacre de argila, conhecido como nódulo, onde também aparecem inscrições com nomes próprios e impressões de selos. Outro suporte onde ocorrem inscrições em linear B são os jarros, principalmente com alças em estribo (Ozanne, 1990 p. 134-6).

A presença de tabletes, nódulos e vasos com inscrições indicam que em seu local de achado escrevia-se e/ou lia-se a língua grafada no linear B (Figura 2). Até 1950 pensavase que o domínio dos registros escritos fosse uma exclusividade dos palácios, os únicos com poder econômico suficientemente centralizado para manter um arquivo, como ocorria nos palácios do Oriente Próximo. Mais uma surpresa estava reservada para os pesquisadores já que, durante as campanhas de escavação da década de 50, diversos tabletes foram encontrados em Micenas, fora do contexto palacial da cidadela, ou seja, em construções de caráter privado como a "Casa do Mercador de Óleo", a "Casa das Esfinges", a "Casa dos Escudos" e outras (Wace, 1939-1955).

A presença do linear B foi atestada em toda a ilha de Creta, sendo que no continente foram encontrados tabletes, nódulos ou jarros em Micenas, Tirinto, Pilos, Tebas, Elêusis, Kreusis e Orcômenos. Esses documentos, revelados em diferentes regiões, embora não tenham a amplitude dos da sala de arquivos do palácio de Pilos, permitem afirmar que todas essas administrações, tanto em casos privados como públicos, utilizaram o mesmo tipo de contabilidade, empregando os mesmos mecanismos administrativos, os mesmos sistemas de pesos e medidas, utilizando a mesma língua. Estavam, pois, a serviço de uma mesma cultura. Em resumo, a cultura micênica, e isso é corroborado pelos outros dados arqueológicos, apresentava durante o Heládico Recente III B, ou seja, o século XIII a.C., uma comple- 
ta homogeneidade abrangendo uma área geográfica que cobria desde as fronteiras da Beócia ao Norte até a ilha de Creta ao sul.

Em 1952, Michael Ventris publica os resultados de sua pesquisa e demonstra ter decifrado o linear B. Novamente a comunidade científica foi surpreendida, surpresa essa que acometeu o próprio responsável pelo deciframento: o linear B foi a primeira forma de grafar-se a língua grega (Chadwick \& Ventris, 1973). E isso era realmente novo e inesperado. Pela primeira vez era possível combinar a análise dos dados arqueológicos relativos ao segundo milênio a.C. com o exame de textos contemporâneos que, embora lacônicos e limitados, são testemunhos indispensáveis da organização política, econômica e social dos estados micênicos da Grécia continental e de Creta durante a Idade do Bronze Recente (Figura 1).

A contribuição do linear B, do ponto de vista político, foi mostrar que existia uma divisão territorial dentro do âmbito de domínio palacial. As evidências mais claras são provenientes dos tabletes de Pilos que, como é sabido, era um palácio que geria uma região compreendendo 2/3 do que é a atual Messênia, limitada ao norte pelo rio Neda e ao sul pelo golfo. Os tabletes também mostraram que o reino era dividido em duas províncias cuja fronteira era a cadeia montanhosa do Aigaleon (a3-ko-ra-i-ja) citada por Estrabão e ao pé da qual foi construído o palácio de Pilos. Assim as províncias aparecem nos tabletes como de-we-ro-a3-ko-ra-i-ja, onde de-we-ro é igual a deuro, em grego "deste lado", e pe-ra-a3ko-ra-i-ja, onde pe-ra é igual ao grego pera, "para além". A província próxima, por sua vez, era dividida em nove distritos enquanto a distante era dividida em sete. Muitos outros topônimos foram identificados no continente e em Creta, Cnossos parece ter dominado a Creta ocidental, central e boa parte da Creta oriental (Hooker, 1976) (Figura 3).

No que diz respeito a relações internacionais os tabletes são mudos, mas temos que ter em mente que as relações registradas nos tabletes têm sempre um caráter local e quando muito regional. Essa limitação pode ser devida a dois fatores que residem no campo hipotético: o primeiro seria que os tabletes eram um registro apenas local relativo ao campo de ação econômica do palácio ou do comerciante que fazia o registro; o segundo seria que os tabletes eram apenas uma forma provisória de anotação sendo que os reais arquivos eram escritos em pergaminho ou papiro. Essa segunda hipótese tem sido reforçada pelos estudos de grafia que concluíram, através da complexidade gráfica dos desenhos dos silabogramas, que a escrita linear B foi desenvolvida para ser pintada e não incisa através de um estilete. Mas sabemos que, através dos textos egípcios e orientais bem como por diversos achados arqueológicos, os palácios de Tirinto, Pilos, Micenas, Tebas e Cnossos participaram do cenário internacional. Em 1964 foi encontrada no Egito uma estela gravada no Templo dos Mortos, dedicada a Amenófis III. Aí aparece uma lista de topônimos cretenses e continentais entre os quais Cnossos, Kydonia, Amnissos e Lictos, em Creta e Micenas, Nauplia e Tegéia entre outras.

Do ponto de vista da sociedade, os tabletes portam diversos qualificativos profissionais, nomes estes que permitem vislumbrar um panorama da estrutura social de um reino micênico (Godart, 1990, p. 217 ss.). Uma das discussões mais freqüentes refere-se à definição das atribuições e funções de dois títulos que aparecem nos tabletes: o basileus (qa-si-reu) e o wanax (wa-na-ka). Tanto nos tabletes de Cnossos como nos de Pilos fica evidente que o sistema de governo era monárquico, sendo o wa-na-ka o soberano único. Muito do que ainda é discutido refere-se à determinação de suas funções, que parecem envolver um caráter religioso e jurídico além do político-econômico, e à questão de estabelecer-se se um dentre os diversos wa-na-kes regionais era visto como chefe supremo de todo o sistema 
político micênico, ou seja, se um dentre os reis era considerado como rei supremo, especialmente no que diz respeito a assuntos internacionais. Já o qa-si-re-u era um líder regional, operando em nível local da hierarquia sócio-política. Se observarmos, mesmo de maneira superficial, o que nos revelam os dados arqueológicos da Grécia pós-palacial, é fácil perceber por que o termo basileus foi utilizado por Homero para designar o rei, em lugar do termo micênico wanax. Após o colapso dos palácios, a Grécia micênica sofreu uma literal pulverização do poder central exercido pelo wanax. Embora não tenhamos registros escritos desse período é notório que os grandes centros desintegraram-se em pequenos núcleos. Rapidamente, com o desaparecimento do poder central, as autoridades locais passaram a exercer, mesmo em escala reduzida a uma pequena aglomeração ou vila, os poderes antes detidos pela autoridade palacial. Assim, o basileus local desempenhava o papel de rei local e a vila passou a reproduzir um microcosmo do palácio (cf. também Chadwick \& Ventris, 1973 e Di Fidio, 1987).

A estrutura de poder micênica coloca o wanax em seu ápice, seguido pelo corpo palacial com seus oficiais e funcionários administrativos. O segundo em importância, após o wanax, seria o lawagetas cuja função ainda é obscura. É aceito que se tratava de um comandante militar ou que uma de suas funções fosse a de deter a chefia militar em tempos de guerra. Abaixo do lawagetas estavam os te-re-ta ou telestai, que também recebiam porções de terra e prestavam serviços ao palácio; esse status também era desfrutado pelos $e$-qeta. Esses quatro níveis determinam a casta palacial diretamente ligada ao wanax. Havia também títulos locais: o qa-si-re-u representava o chefe local; a ele estavam ligados os kore-te e os po-ro-ko-re-te, respectivamente um tipo de prefeito e seu adjunto.

Novamente deve-se ressaltar a especificidade dos registros grafados nos tabletes. A contabilidade era registrada, em primeira instância, em tabletes de argila crua e posteriormente o essencial era reportado para um material mais nobre. Esses registros anuais foram destruídos durante o mesmo incêndio que preservou os tabletes de argila, os "rascunhos" se assim podemos chamá-los. Dessa forma, hoje temos apenas uma parte dos registros contábeis do último ano de existência desses palácios. Contudo, o linear B não apareceu simplesmente da noite para o dia; a escrita teve um desenvolvimento que nos escapa completamente hoje mas que muitos epigrafistas tentam reconstituir.

Os pesquisadores concordam que o linear B originou-se a partir de uma forma arcaica do linear A com a qual os micênios tomaram contato através de sua presença em Creta, principalmente em Cnossos onde também conheceram formas complexas de administração econômica. Mas a necessidade de adaptar-se a língua grega dos micênios à escrita minóica só surgiria por volta de 1600 a.C., a partir do momento em que a Grécia continental fosse suficientemente desenvolvida para ter o que gerir. $\mathrm{O}$ aparecimento da escrita obedece a exigências de caráter econômico: quando o patrimônio a ser gerido ultrapassa os limites da memorização é necessário criar-se um sistema para registrá-lo e isso acontece quando uma sociedade atinge um certo grau de desenvolvimento e prosperidade econômica. A melhor prova que temos disso são os objetos encontrados nos círculos tumulares de Micenas; tamanha riqueza só poderia ser fruto de um intenso intercâmbio comercial de matériasprimas preciosas e inexistentes no continente grego. Assim, é aceito hoje que a escrita apareceu em Micenas entre o final do século XVII e o começo do século XVI a.C (Godart, 1990, p. 99 e ss.).

Nessa época os micênios já apresentavam, devido ao seu estágio de desenvolvimento, a necessidade de gerir de forma organizada seu patrimônio e para tanto voltaram-se 
para os minóicos com os quais mantinham há muito tempo relações comerciais e deles tomaram o sistema de escrita para adaptá-lo à língua grega, certamente diferente daquela falada pelos cretenses. Essa transformação resultará no linear B utilizado pelos micênios e assim, partindo de Micenas, essa escrita penetraria em todas as administrações micênicas refletindo o quadro homogêneo que os tabletes nos apresentam.

Mas em um determinado momento, em Cnossos, a capital minóica, o linear B tomou o lugar do linear A como escrita oficial do palácio. Nesse momento, os micênios tomaram o poder em Cnossos impondo a sua língua como a oficial. Embora seja difícil reconstruir eventos de tamanha amplitude parece que os micênios aproveitaram um momento de crise do poder minóico, destituíram-nos e substituíram todas as administrações locais minóicas e centralizaram o poder em Cnossos para controlar toda a ilha. Essa dominação parece resultado da disputa pelas rotas comerciais dominadas anteriormente pelos minóicos que eram os intermediários entre o Egito e a costa anatólica. A disputa por tais rotas comerciais continuou entre os micênios de Creta e os do continente, tendo sido ganha definitivamente pelos continentais, pois que Evans datou a destruição definitiva de Cnossos no começo do século XIV a.C. Isto é confirmado também pelos textos egípcios que não mencionam mais os cretenses a partir do final do reino de Amenófis III, mas a presença micênica na ilha continuou até por volta de 1200 a.C., quando tanto os palácios de Creta quanto os continentais desaparecem e com eles a escrita linear B.

Então, é possível perceber o quanto as evidências do linear B foram decisivas para a constituição de uma história da Grécia micênica. Tanto os suportes da escrita, ou seja, os tabletes, os nódulos e os vasos com inscrições, como aquilo que neles foi escrito mudaram a perspectiva histórica dos pesquisadores e o que parecia coerente passou a ser visto de um outro ponto de vista. A contribuição do linear B foi inestimável e continua sendo de importância capital pois a cada novo tablete, a cada nova inscrição, uma nova linha de questionamento é aberta e cada vez mais nos é possível compreender esse período. O mito relatado por Homero passou a ser arqueológico com as contribuições de Evans e Schliemann, tornando-se histórico com Michael Ventris e tantos outros que dia a dia trabalharam e trabalham na reconstrução do passado micênico da Grécia.

\section{Referências bibliográficas}

BLEGEN, C. W. \& RAWSON, M. The palace of Nestor at Pylos in Western Messenia. Princeton: Princeton University Press, 1966.

CHADWICK, J. \& VENTRIS, M. Documents in Mycenaean Greek (2. ed.). Cambridge: Cambridge University Press, 1973.

CHADWICK, J. The Mycenaean World. Cambridge: CambridgeUniversity Press, 1976.

DI FIDIO, P. Palais et communautés de village dans le royaume de Pylos, Tractata Mycenea. Ohrid 1985, Skopj, 1987.

EVANS, A. J. The Palace of Minos at Knossos. Londres: s. ed., 1921.

GODART, L. Le pouvoir de l'Écrit. Paris: Armand Collin, 1990.

Le linéaire B et son environnement. Studi Micenei ed Egeo Anatolici, XX (1979), p. $27-42$. 
HOOKER, J. Mycenaean Greece. Londres: Thames and Hudson, 1976.

OZANNE, I. Les mycéniens: pillards, paysans et poète. Paris: Arand Collin, 1990.

TREUIL, R.; DARCQUE, P.; POURSAT, J.-C.; TOUCHAIS, G. Les civilisations égéennes du Néolithique et de l'Âge du Bronze. Paris: PUF, 1989.

WACE, A. J. B. Excavations at Mycenae: 1939-1955 (ed. E indexado por Elizabeth French). Annual of the British School at Athens, vols. 45-56. Londres: Thames and Hudson, s/d.

TORRALVO, A. C. Linear B: the specificity of an evidence and its contribution for the Mycenaean studies. Classica, São Paulo, 11/12, p. 149-157,1998/1999.

\begin{abstract}
We have two moments in the history of the Greek proto-historic archaeology: after and before the discovery of the three different Aegean scripts. In: 1952 the Linear B was deciphered by Michael Ventris and an important verification was made: the language that was written in the tablets was Greek, in that way a kind of revolutions started inside the established historical framework: Crete, where the Minoan culture had developed, one day was dominated by the Mycenaeans, Greek speakers from the mainland! With the decipherment, the archaeologists and epigraphists worked together to rewrite the Aegean history during the second millenium b.C. A new universe was revealed by the tablets although they revealed just administrative records related to the time when the palace was destroyed. These tablets contain important records about territorial and work division, donations with names of gods, social information... With each new tablet that is found, a little more about the history of the Greek proto-history is revealed.
\end{abstract}

KEY-WORDS: Linear B; Script; tablets; Mycenaean; Minoan; palacial administration; Greek proto-history. 


\begin{tabular}{|c|c|c|c|c|c|c|c|c|c|c|c|}
\hline K & $\mathrm{P}$ & M & $\mathrm{T}$ & K & $\mathrm{P}$ & M & $\mathrm{T}$ & K & $P$ & M & $\mathrm{T}$ \\
\hline 15 & $F$ & $t$ & $r$ & $30 Y Y$ & $Y Y$ & $x y$ & 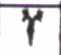 & $59 L F$ & 4 & FE & C \\
\hline$=t$ & $t$ & $t$ & $t$ & $31 \times r$ & $\psi \gamma$ & $\uparrow \kappa$ & & $60 \mathrm{ksk}$ & 1646 & $10 \leq t$ & \\
\hline $3 \neq$ & $\neq$ & $\neq$ & & $32 Y \neq \dagger$ & $\begin{array}{llll}2 & 4 & 4 & 4\end{array}$ & $4+4$ & & 6. BEBM & $B D$ & and & 06 \\
\hline 4 a & w & $中$ & $\phi$ & & $\Psi Y$ & & & ${ }_{62} M Y$ & M M & & \\
\hline$s \mp \bar{T} \bar{T}$ & $\mp 7$ & $\mp \mp$ & $\mp$ & $34<<($ & 6 & & & & ' & & \\
\hline $6 \div \overline{9}$ & $\overline{7} \overline{9}$ & $\bar{\varphi} \bar{q}$ & 1 & $35 \uparrow \uparrow$ & $b$ & & & 64 咸 & 型 & & \\
\hline 7 吕 & $m$ & T & m & ${ }_{36} Y 5 T$ & $57 \%$ & $5 \%$ & $7 \%$ & os 植楮 & 情的 & & \\
\hline $8 T 4$ & $\psi$ & $|\varphi|$ & 本 & $37 \AA \cap$ & $A$ A & A & A) & 66 箅 & 国 & & \\
\hline${ }_{Q} F$ & $F$ & $F$ & & $3^{8} A A$ & AAिA & $A A A$ & 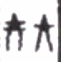 & 67 V & 174 & $\forall \nabla$ & \\
\hline $10 \quad f$ & $A f$ & F & $\Gamma$ & 39 स & 虫 & 舴 & 告 & $68 \phi \phi b$ & 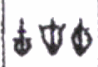 & & \\
\hline$\therefore 57$ & 55 & 与多 & & 40 a a & 6 & 在 & 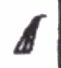 & 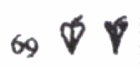 & $\nabla \psi$ & $\phi$ & \\
\hline $12 भ 9$ & 74 & 4 & 9 & 42 为息 & 我为 & 光为市 & & ${ }_{70} 99$ & 99 & 97 & 9 \\
\hline${ }_{13}$ os 7 & $p$ & $7 p_{3}$ & nes & $42 \Delta A^{\prime} \Delta$ & $A^{\prime} D^{3} 8$ & $\vec{A} \quad \dot{\Delta}$ & & 71298 & H & & \\
\hline${ }_{14} \uparrow \varphi$ & $p q$ & F & 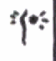 & ${ }_{43} \times 1 \times 4$ & 肾简 & & & $72 E F$ & DE & $E D B$ & \\
\hline 15 귁 & of & 키 & (9) & 44 策 & $x x$ & 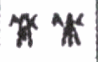 & & ${ }_{73} V V$ & $\forall V$ & V & \\
\hline${ }_{16}+p$ & $p \phi$ & 9 & & $45 \times$ & $x \times$ & $x \times$ & $x^{2}$ & ${ }_{74} \mathrm{CE}$ & k & & \\
\hline $17+\& f$ & f & $\beta$ & & ${ }_{46} x x$ & $x$ & & & 752 & 2 & 22 & 2 \\
\hline $18 \ngtr 8$ & & & & 4) & & $x$ & & $76 \| 18$ & $\| \pi$ & & \\
\hline 198 & & & & ${ }_{48} \times X^{\prime \prime}$ & "x" & $\stackrel{4}{n}$ & & $7 \oplus \oplus$ & $\oplus$ & $\oplus \oplus$ & $\theta$ \\
\hline $20 \uparrow \uparrow$ & $\uparrow$ & $\uparrow$ & $f$ & $49 \tilde{H}$ & & & & $78 \Theta \theta$ & $\Theta \theta$ & $\odot \Leftrightarrow$ & \\
\hline $21 T \%$ & T T & $\alpha \%$ & & so $\mathbb{1}$ & 百 & 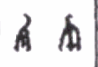 & & 798 & 0 & (i) & \\
\hline 22$\rceil 7$ & & & & s1 कै तो & 而 & $x$ & & $80 \%$ & dit 6 & $x$ & 219 \\
\hline${ }_{23} T Y Y$ & $T Y$ & & & $52 * 4$ & $\%$ & 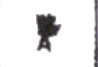 & 12 & 81 列 & h中s & $\phi \phi$ & $-\xi$ \\
\hline${ }_{24} \Psi \Psi$ & us op & 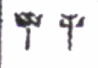 & $\Psi$ & ${ }_{53} \downarrow l 1$ & $d x$ & $9 x$ & * & ${ }_{82} C$ & $\%$ & & 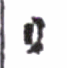 \\
\hline $25 T$ & 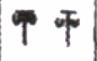 & $\bar{p}$ & & 54 成 & 闲 & 用策 & 角 & 83 F & in & & \\
\hline $26 \uparrow \Psi$ & $\uparrow q$ & $\Psi$ & $\tilde{I}$ & ss 比州 & $|n| A|k|$ & & H & $8 4 \longdiv { 3 }$ & & & \\
\hline $27 \quad \psi$ & $\Psi$ & $\dddot{i}$ & & 56 光 & $\mathrm{HA}$ & & & ${ }_{85} 902$ & in & is & \\
\hline $28 \psi \psi$ & $\psi \psi$ & $\psi \psi$ & & 57 日具 & 昌目 & 皇 $\mathrm{日}$ & & $86 \Delta$ & L & & \\
\hline $29 \% \psi$ & $Y Y$ & $\psi \psi$ & & $58 \mathrm{PE}$ & $E P$ & $E^{-1}$ & E & $87 \quad B$ & & & \\
\hline
\end{tabular}

Fig. 1 - O silabário micênico (segundo Bennett), a partir de Chadwrick \& Ventrio, 1973. 


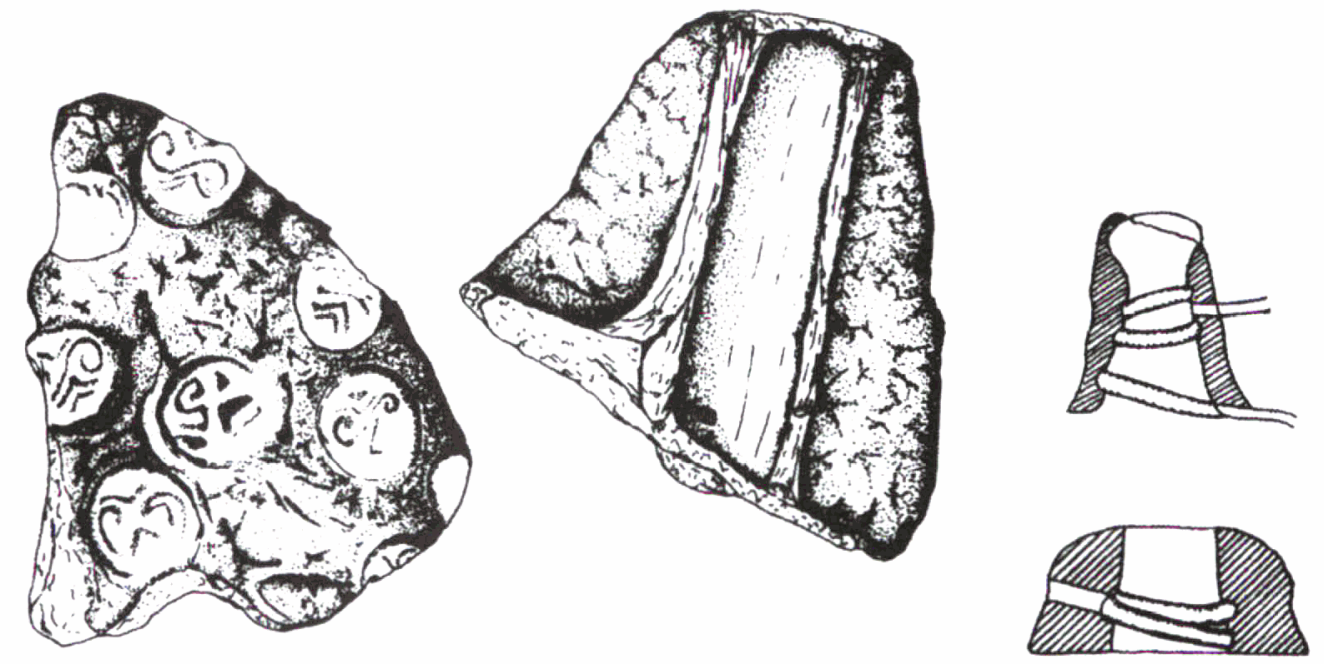

Fig.2 - Impressões de selo em nódulo de Monastiraki. A parte selada do nódulo (esquerda) e o verso (centro) com a marca do recipiente. À direita, esquema de amarração de lacres, os quais também eram selados.

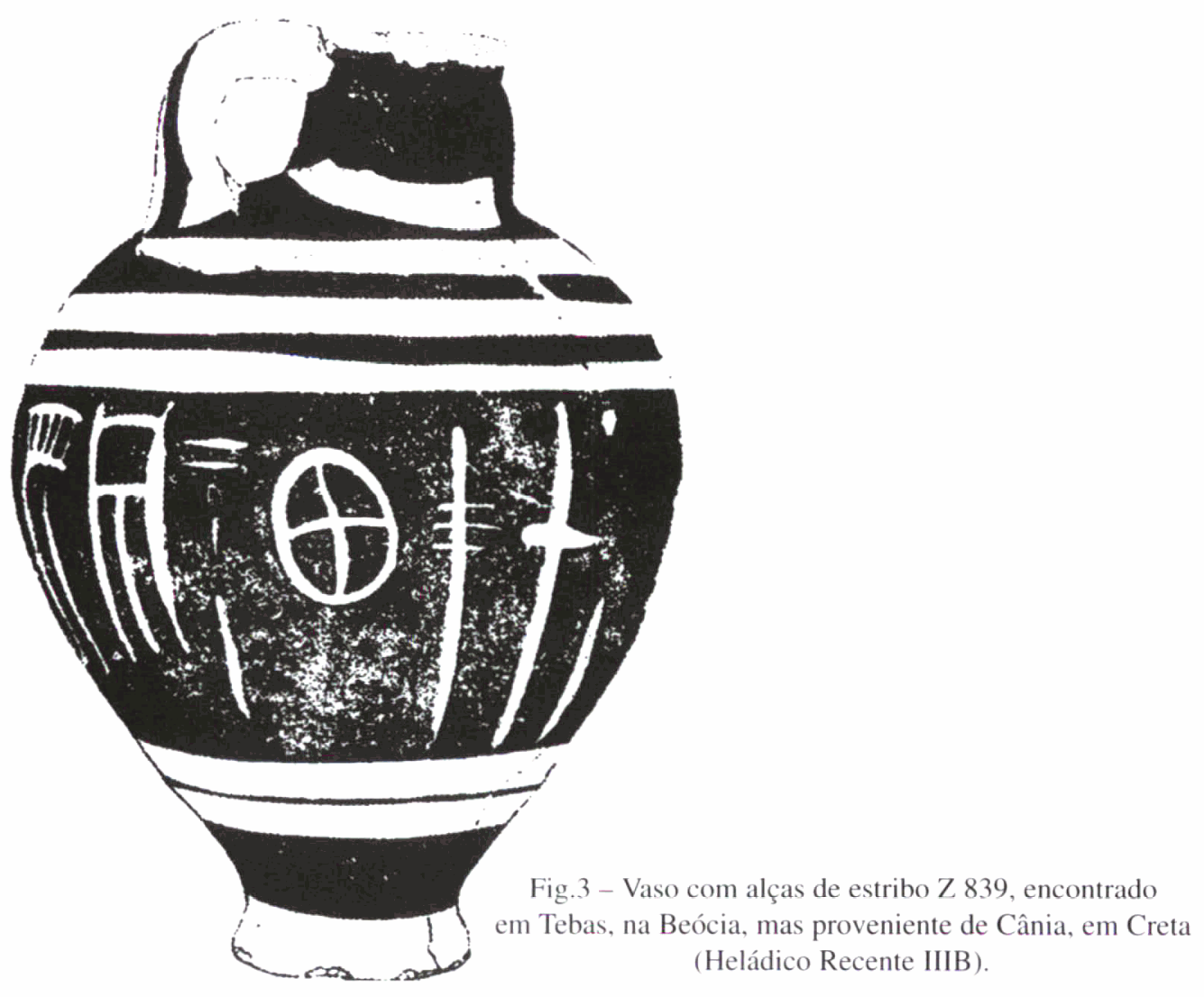




\section{Transliteração}

2 [i]-qi-ja / a-ja-me-na e-re-pa-te a-ra-ro-mo-te-me-na a-ra-ru-ja [a-ni-ja-pi] 1 e-re-pa-te-jo o-po-qo ke-ra-ja-pi o-pi-i-ja-pi ko-ki-da o-pa

\section{Tradução}

Três carros sem rodas engastados com marfim, (completamente) equipados, decorados com marfim e pedaços de chifres. A contribuição de Kolkhidas.

Fig 4. - Tablete em Linear B dito do "carro" encontrado no "Arsenal" de Cnossos em 1909 (265 = Sd0403). Transliteração e tradução a partir de Chadwick \& Vendris, 1973, p. 366). 